\title{
MELODIC ANALYSIS OF SPEECH (MAS): APLICACIONES EN LA COMPARACIÓN DE LENGUAS
}

Dolors FONT-ROTCHÉS

Laboratori de Fonètica Aplicada. Universitat de Barcelona

\section{RESUMEN}

En este artículo, presentamos un análisis comparativo de la entonación de las preguntas absolutas del español, del catalán y del portugués de Brasil a partir de las investigaciones que se han llevado a cabo en los últimos años por el grupo Entonación y Habla de la Universitat de Barcelona. Se trata de una comparación formal entre los diversos patrones que utiliza cada lengua para producir este tipo de preguntas. Para realizar esta investigación, nos hemos basado en el método Melodic Analysis of Speech (MAS), descrito por Cantero (2002), revisado y ampliado por Font-Rotchés (2007) y, posteriormente, establecido por Cantero y Font-Rotchés (2009), después de haber sido aplicado en distintas investigaciones sobre descripción de la entonación de distintas lenguas e interlenguas.

\footnotetext{
ABSTRACT

In this paper, we present a comparative analysis of the intonation of absolute questions in Spanish, Catalan and Brazilian Portuguese based on research carried out during the last few years by the group Intonation and Speech from the University of Barcelona. This is a formal comparison between the different patterns that each language uses to produce this type of question. For this research we have used the Melodic Analysis of Speech method (MAS) described by Cantero (2002), revised and extended by Font-Rotchés (2007) and subsequently established by Cantero and Font-Rotchés (2009), after having been applied to different research projects regarding the description of intonation in different languages and interlanguages.

PALABRAS-CLAVE Entonación. Preguntas absolutas. Español. Catalán. Portugués de Brasil. Método Análisis Melódico del Habla.

KEY WORDS Intonation, Absolute questions. Spanish. Catalan. Brazilian Portuguese. Melodic Analysis of Speech method.
} 


\section{Introducción}

El estudio de la entonación de las lenguas es de gran interés porque tiene aplicaciones en el campo del análisis, síntesis y reconocimiento de la voz, en los sistemas de diálogo, en fonética forense, en fonética clínica (reeducación de la voz, trastornos del habla) y también en la descripción lingüística y en la enseñanza de lenguas. Es en este último campo en el que el grupo Entonación y Habla de la Universitat de Barcelona se ha especializado.

Para realizar el análisis de la entonación de las lenguas, utilizamos el método Melodic Analysis of Speech (MAS), también llamado Análisis Melódico del Habla, propuesto por Cantero (2002), revisado y ampliado en Font Rotchés (2007) y establecido en Cantero y Font-Rotchés (2009) y Font-Rotchés y Cantero (2009). Se trata de un método muy adecuado para este tipo de investigaciones, cuyos resultados son útiles para desarrollar aplicaciones didácticas en la enseñanza de primeras y segundas lenguas. Frente a otros métodos de análisis de la entonación, ofrece un criterio de segmentación de las melodías del habla exclusivamente fónico y presenta un sistema de procesamiento de los datos acústicos que nos permite obtener los valores relativos que constituyen las melodías, para compararlas, clasificarlas, reproducirlas con toda fidelidad, experimentar con ellas mediante la síntesis de voz, someterlas al análisis perceptivo y hacer generalizaciones lingüísticas.

Así pues, podemos contar con múltiples informantes y un gran número de contornos, que nos han servido para establecer con precisión los patrones entonativos de una lengua: español (Cantero y Font-Rotchés, 2007), catalán (Font-Rotchés, 2007), así como el estudio de la interlengua: español hablado por taiwaneses (Liu, 2005), por brasileños (Fonseca y Cantero, 2011), por italianos (Devís, en prensa), por suecos (Martorell, en prensa) o catalán hablado por húngaros (Pálvölgyi, 2010), por citar algunos de los estudios que se están llevando a cabo.

En este artículo, presentamos las características esenciales del método acompañadas de un ejemplo de las aplicaciones que se pueden desarrollar: la descripción de los patrones interrogativos de tres lenguas, español, catalán, y portugués de Brasil, y la comparación formal entre ellos. Por consiguiente, hemos podido establecer las semejanzas y diferencias que tienen los patrones interrogativos de estas tres lenguas románicas, gracias a las características del método: se obtienen patrones melódicos con unos márgenes de dispersión expresados en valores exactos, en porcentajes, con lo cual tenemos la información necesaria para desarrollar aplicaciones 
didácticas en el ámbito de la enseñanza-aprendizaje de primeras y segundas lenguas y de lenguas extranjeras.

\section{E1 método Melodic Analysis of Speech (MAS) ${ }^{1}$.}

En nuestros trabajos de entonación, hemos desarrollado un modelo teórico que nos permite identificar con toda precisión las unidades fónicas del habla, independientemente de cualquier otro nivel de análisis. Ello nos permite describir la entonación de un corpus de habla no preparado ni inducido, totalmente ajeno a la intervención de los investigadores, con informantes anónimos y con habla espontánea genuina.

Este planteamiento es diferente al que mantienen los estudios de la entonación que se elaboran a partir de un corpus de "habla de laboratorio" (frases preparadas y leídas o, como mucho, inducidas por el investigador) y conlleva un tipo de análisis que no puede describir la realidad lingüística tal cual es, sino únicamente una realidad lingüística creada en el laboratorio, que, obviamente no es muy "real".

El modelo teórico, expuesto en Cantero (2002), se basa en el concepto de jerarquía fónica, según el cual el habla está formada por unidades fónicas trabadas, bien jerarquizadas: la sílaba, el grupo rítmico (o palabra fónica) y el grupo fónico. La unidad de análisis de la entonación es el grupo fónico (con una melodía determinada); la unidad de análisis del ritmo es el grupo rítmico (cuya melodía también es relevante dentro del contorno); y la unidad de análisis de la melodía es el segmento tonal (es decir, el valor tonal, relativo, del núcleo silábico: la vocal). Cada vocal, entonces, constituye un segmento tonal, excepto las vocales tónicas, que pueden constituir una inflexión tonal, es decir, dos (o más) segmentos tonales: como ocurre en el acento de frase, que es el núcleo del grupo fónico y, por tanto, también el núcleo de la melodía. La presencia de una inflexión tonal será el criterio formal que utilizaremos para delimitar el grupo fónico.

Ante un corpus de habla espontánea, y en un primer momento, conviene seleccionar los enunciados que coinciden con un turno de palabra del diálogo (normalmente breves y fáciles de identificar) hasta que el investigador no haya adquirido la suficiente confianza en la identificación de los grupos fónicos y en la delimitación de las melodías del habla.

Una vez identificadas las unidades melódicas (los grupos fónicos), hay que tratarlas como enunciados autónomos. Cada una contendrá, en unas ocasiones,

\footnotetext{
${ }^{1}$ Este apartado sigue de cerca el protocolo expuesto en Cantero y Font-Rotchés, 2009.
} 
sintagmas más o menos definidos y, en otras, oraciones más o menos completas gramaticalmente (ya que trabajamos con lengua oral espontánea): pero en ningún caso dependemos de estas unidades gramaticales para el análisis, porque las unidades que analizamos son unidades fónicas (contengan o no unidades gramaticales, enteras o no). Nosotros creemos que son más bien las unidades gramaticales las que ubican y se adaptan a su contenedor melódico, que es el auténtico estructurador del discurso oral: lo que llamamos entonación prelingüistica.

\subsection{Fase acústica: determinación de los valores frecuenciales relevantes $y$ estandarización}

Utilizando Praat (Boersma \& Weenink, 1992-2010), la aplicación de análisis acústico y síntesis con gran aceptación dentro de la comunidad investigadora, determinamos la media de los valores de $\mathrm{F}_{0}$ de la vocal de cada enunciado (en $\mathrm{Hz}$ ), o el valor central cuando es lo suficientemente estable. Cuando se trata de una vocal tónica que contiene una inflexión tonal, hemos de determinar el valor de los dos segmentos tonales que constituyen la inflexión (o de los tres segmentos, si la inflexión es circunfleja). Estos valores se calculan de los valores extremos de la inflexión. Otras veces, la inflexión tonal final comienza en una vocal tónica y acaba en la vocal átona, como ocurre en las inflexiones finales que coinciden con una palabra llana o esdrújula. En el caso de que la inflexión final acabe en una vocal seguida de una consonante nasal o lateral, esta consonante sonante podría constituir, por sí misma, el último segmento tonal de la inflexión.

Los valores absolutos obtenidos en esta primera fase del análisis (v. fila 'herzios' en tabla 1) no constituyen aún, sin embargo, la melodía del contorno, son datos en bruto que han de procesarse adecuadamente. El segundo paso en el análisis melódico es, pues, la estandarización de los datos frecuenciales, es decir establecer la distancia tonal en porcentajes entre un segmento tonal y el siguiente: el ascenso tendrá un porcentaje positivo y el descenso, negativo (v. fila 'porcentaje' en tabla 1).

\begin{tabular}{|l|c|c|c|c|c|c|c|}
\hline Enunciado & Te & ca & be & to(do) & a & hí & hí $^{*}$ \\
\hline Herzios & 277 & 277 & 340 & 320 & 296 & 311 & 532 \\
\hline Porcentaje & $100 \%$ & $0,0 \%$ & $22,7 \%$ & $-5,9 \%$ & $-7,5 \%$ & $5,1 \%$ & $71,1 \%$ \\
\hline Curva estándar & 100 & 100 & 123 & 116 & 107 & 112 & 192 \\
\hline
\end{tabular}

Tabla 1. Valores absolutos y estándares de ¿'Te cabe todo ahí?. 
Para hacer la representación gráfica de una melodía, convertimos los porcentajes obtenidos a valores estándares (v. fila 'Curva estándar' en tabla 1): comenzando, por ejemplo, por el valor 100 (un valor arbitrario), le aplicamos el porcentaje de ascenso que ha sufrido el segundo segmento, $0 \%$, y obtenemos el segundo valor, 100; a este, se le aplica el porcentaje de ascenso del tercero, $+22,7 \%$, y obtenemos el tercer valor, 123 ; y así, sucesivamente, hasta el último segmento.

Con la aplicación de esta primera fase del método, o fase acústica, se obtiene la estandarización de los contornos, que ahora ya son comparables y clasificables, independientemente de la edad, el sexo o cualquier otra característica del informante, ya que se han extraído todas las variaciones micromelódicas y se han normalizado los valores (a partir de un valor arbitrario 100). Tampoco hay que preocuparse por el número de informantes del corpus, ya que con la aplicación del método todos los contornos obtenidos son directamente comparables.

\subsection{Fase perceptiva: validación del análisis e interpretación de los datos}

Después de la fase acústica, podemos comprobar la validez de nuestros resultados mediante una serie de pruebas perceptivas en las que sometemos a juicio de los oyentes una copia exacta (por síntesis de voz) de la frase analizada.

Utilizamos el programa Praat para obtener esta copia sintetizada (con el método PSOL $A$ ), de la cual borramos todos los datos originales y los sustituimos por nuestros datos estandarizados. Así comprobamos que, efectivamente, el análisis melódico ha sido correcto y refleja la melodía original, sin variaciones micromelódicas y con los valores normalizados, es decir, se trata de una melodía idéntica a la original, pero con una tesitura de voz diferente.

El siguiente paso es, evidentemente, interpretar adecuadamente la melodía obtenida: extraer los datos melódicos relevantes que permiten una interpretación del contorno, por ejemplo una interpretación fonológica.

En nuestro modelo teórico, distinguimos entre los rasgos melódicos de los contornos (que constituyen el nivel fonético de la entonación) y los rasgos fonológicos (que permiten establecer los tonemas o unidades fonológicas de la entonación).

Los rasgos fonológicos que contemplamos son: / \pm Interrogativo/ / \pm Enfático/ y / \pm Suspendido/, cuya combinación nos ha permitido caracterizar los tonemas de cada lengua (Cantero, 2002). Estos rasgos fonológicos han sido suficientes para clasificar todos los contornos de los diversos corpus que se han elaborado para distintas investigaciones dentro del marco de Laboratorio de Fonética Aplicada. 
Los rasgos melódicos, por su parte, son las características de los elementos funcionales del contorno: el anacrusis, el primerpico, el cuerpo (o declinación), el núcleo y la inflexión final. Entendemos por anacrusis las silabas átonas previas a la primera vocal tónica del contorno, llamada primer pico, por cuerpo las sílabas que van desde el primer pico a la última vocal tónica del contorno o núcleo, y por inflexión final las sílabas que van del núcleo hasta el final del contorno. Es la dirección de esta inflexión final, ascendente, descendente, plana, ascendente-descendente, etc., la que nos permite establecer los patrones melódicos típicos.

Según nuestro método, el patrón melódico no es una mera representación de una línea con ascensos y descensos, sino que es una abstracción de la realidad hablada, representativa de múltiples melodías con los rasgos melódicos comprendidos entre sus márgenes de dispersión (definidos con claridad y cuantificados objetivamente). En estos márgenes se dan las variaciones de que nos servimos los hablantes para transmitir intenciones, emociones y otros contenidos expresivos o bien para evidenciar diferencias socioculturales o dialectales.

\section{Patrones interrogativos del español}

En español, hemos encontrado cuatro patrones /+interrogativos/ resultado del análisis acústico y de las pruebas de percepción que se han llevado a cabo en investigaciones basadas en un corpus de español (Cantero y Font-Rotchés, 2007; Font-Rotchés y Mateo, 2011).

Los patrones se describieron en dos etapas a partir de un total de 55 preguntas absolutas producidas por 47 informantes, hombres y mujeres, con edades comprendidas entre los 16 y los 83 años en el momento de la emisión de los enunciados. Son todos ellos hablantes nativos de las diversas variedades dialectales del español peninsular y de Canarias y de composición totalmente aleatoria por lo que respecta tanto a la ubicación dialectal concreta como al origen social y nivel cultural.

\subsection{Elpatrón Inflexión final ascendente (+70\%)}

El patrón Inflexión final ascendente $(+70 \%)$ se caracteriza por ser /+interrogativo -enfático -suspenso/ y se distingue de los otros porque presenta una inflexión final con un ascenso igual o superior al 70\%, tal como se puede apreciar en el gráfico. 


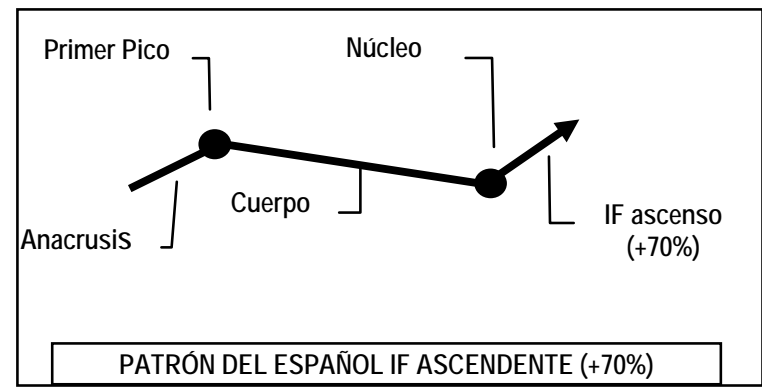

Gráfico 1. Patrón del español IF ascendente (+70\%).

Este patrón presenta un ascenso hasta la primera sílaba tónica o primer pico de un máximo de un $40 \%$, un cuerpo en declinación hasta el núcleo o última sílaba tónica y un ascenso final igual o superior al $70 \%$. Tenemos un total de 12 interrogativas absolutas que responden a los rasgos melódicos de este patrón, de las cuales aportamos unos ejemplos:
a. ¿Y bambas tal vez no?
b. ¿Ustedes estarían por la hospitalización?
c. ¿Me lo puedes repetir?
d. ¿Te cabe todo ahi?
e. Entonces, ¿me puedo quitar la corbata también?

Este patrón se utiliza en preguntas de carácter neutro, para obtener información, aunque también encontramos otros usos, como preguntasruego o un uso casi retórico.

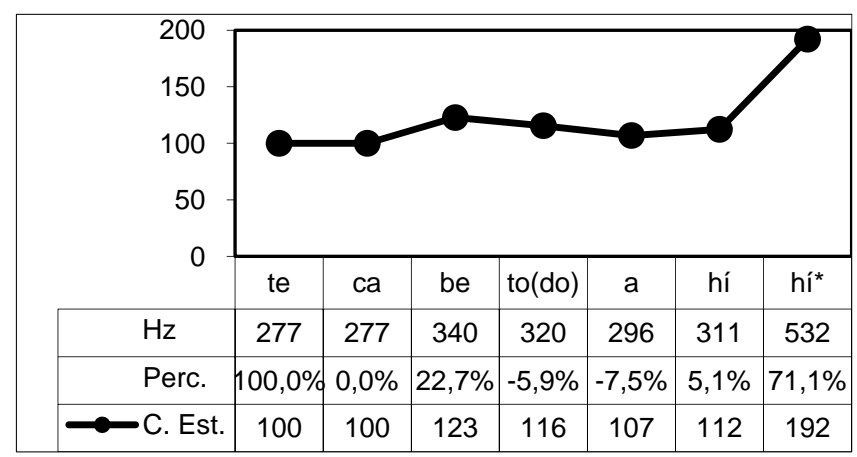

Gráfico 2. Contorno melódico de ¿Te cabe todo ahí? del patrón IF ascendente $(+70 \%)$ del español. 
El contorno del gráfico 2 , ¿Te cabe todo ahi?, presenta un anacrusis con un ascenso total del $23 \%$, que culmina en una sílaba átona posterior a la tónica, -be, que es donde se encuentra el primer pico. Se trata de un pequeño desplazamiento sin gran relevancia. El cuerpo es descendente y la inflexión final presenta un $71,1 \%$ de ascenso en la sílaba tónica final, hi.

\subsection{Elpatrón Inflexión final ascendente (40\% 60\%)}

El patrón Inflexión final ascendente (40\% 60\%), que se caracteriza por ser /+interrogativo -enfático -suspenso/ se diferencia del anterior no solo por una inflexión final con un ascenso inferior, sino también por presentar de manera sistemática un desplazamiento del primer pico a una vocal átona posterior a la primera vocal tónica. Así, pues, como se puede ver en el gráfico 3, el patrón presenta un ascenso hasta una sílaba átona posterior al primer pico de un máximo de un $40 \%$, un cuerpo en declinación hasta el núcleo o última silaba tónica y un ascenso final entre un $40 \%$ y un $60 \%$.

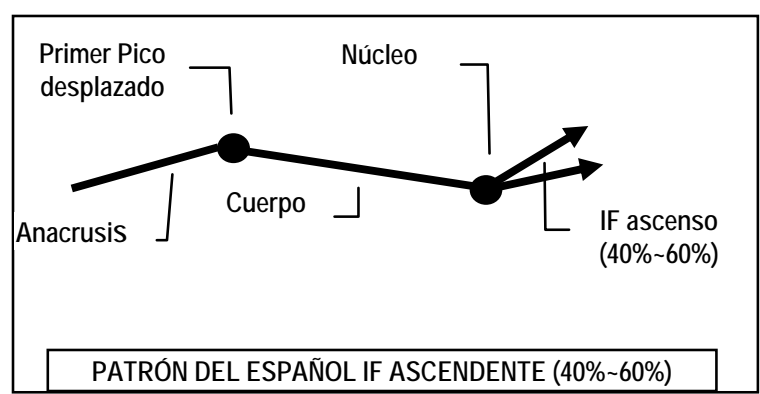

Gráfico 3. Patrón del español IF ascendente (40\% 60\%).

Tenemos un total de 19 interrogativas absolutas que responden a los rasgos melódicos de este patrón, de las cuales aportamos unos ejemplos:

a. ¿Y van a llegar a un acuerdo?

b. ¿Tienes permiso de conducir?

c. ¿Es una indirecta para que me vaya?

d. ¿Hubo miedo?

e. Y por aquí tenéis una cañada real, ¿verdad? 
También en este caso este tipo de contornos fueron utilizados por los hablantes en preguntas en las que básicamente los interlocutores querían obtener una información de carácter neutro, como el ejemplo del gráfico 4, ¿Hubo miedo?, que presentamos a continuación.

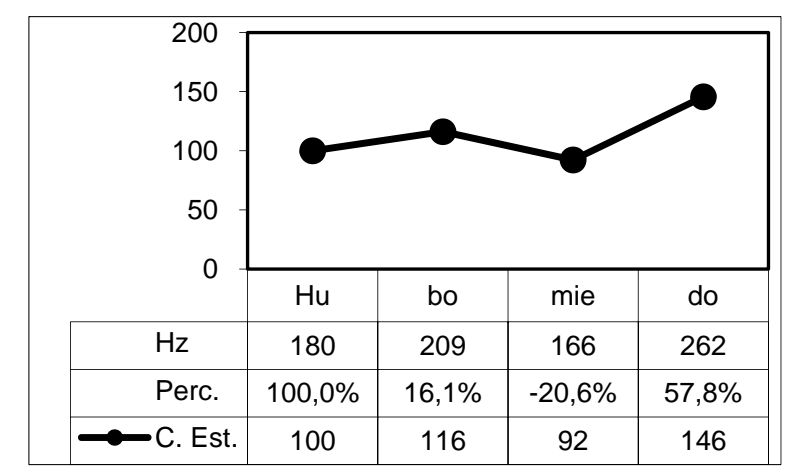

Gráfico 4. Contorno melódico de ¿ Hubo miedo? del patrón IF ascendente (40\% 60\%) del español.

El contorno del gráfico 4 es típico de este patrón. Presenta un anacrusis con un ascenso total del 16,1\%, que culmina en el primer pico, una sílaba átona posterior a la tónica, - $b$, seguido de un cuerpo descendente y una inflexión final que empieza en el núcleo, mie- y asciende un 57,8\% hasta la sílaba $-d o$.

\subsection{El patrón Inflexión final ascendente-descendente}

El patrón melódico IF ascendente-descendente (v. gráfico 5) se caracteriza por un anacrusis con un ascenso suave de hasta un $25 \%$, que llega a un primer pico desplazado a una vocal átona posterior, un cuerpo plano hasta llegar a la última sílaba tónica o núcleo, y una inflexión final circunfleja, ascendente-descendente. El ascenso de la inflexión se percibe a partir del 25\% y tenemos ejemplos que llegan hasta un 55\%. El descenso se prolonga hasta llegar a un punto más bajo de donde había empezado la inflexión. Puede presentar variantes que no contengan anacrusis o que el cuerpo sea descendente. 


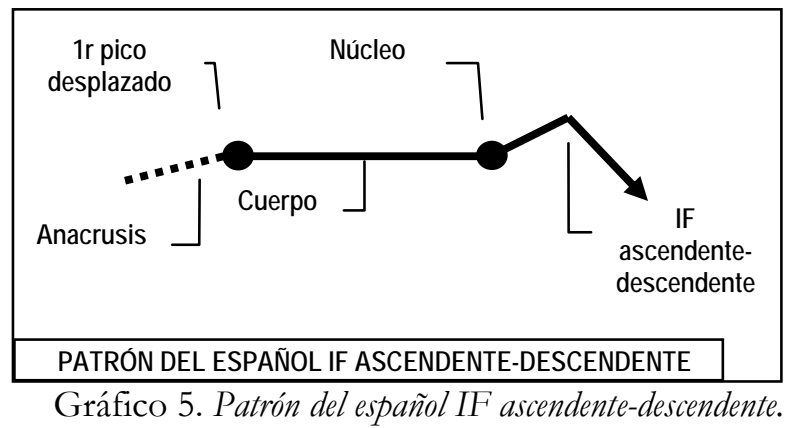

Este tipo de contornos que responden a este patrón, tenemos 7 en total, se utilizan menos que los anteriores ya que requieren de contextos más específicos.
a. ¿'Te gusta el tomate?
b. ¿Eso se está haciendo?
c. ¿Es bonito?
d. ¿Corto yo también?

Vemos en el gráfico 6 un caso típico de este patrón con la pregunta $\dot{i}$ e gusta el tomate?. Empieza el contorno con un ascenso suave hasta una sílaba átona posterior a la primera tónica, te gusta el to-, con un ascenso total de un $15 \%$, sigue en descenso hasta la última sílaba tónica, -ma-, punto donde empieza la inflexión final circunfleja, con un ascenso de un $42,6 \%$ y un descenso de un 34,3\%.

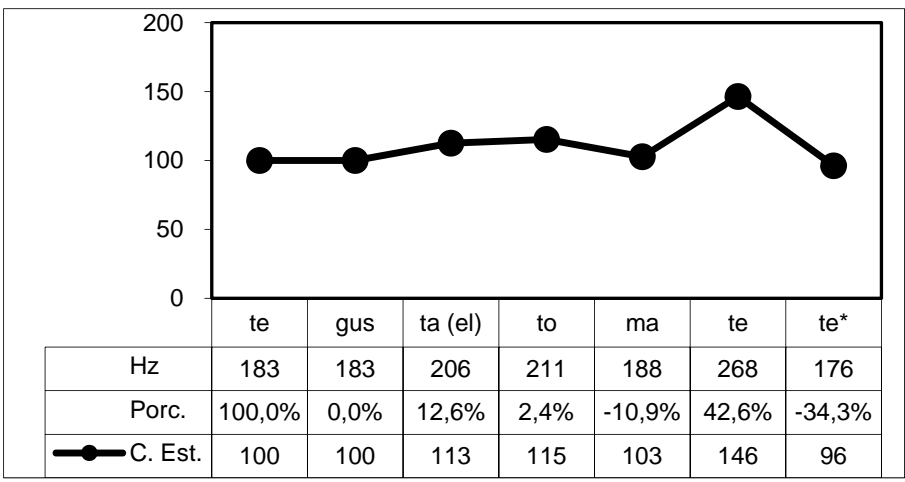

Gráfico 6. Contorno melódico de ¿'Te gusta el tomate? del patrón IF ascendentedescendente del español. 


\subsection{Elpatrón Cuerpo Ascendente}

Este patrón, a diferencia de los otros, lo denominamos Cuerpo ascendente, porque aunque presenta una inflexión final ascendente, la característica que lo distingue del resto de patrones es el cuerpo ascendente que tiene lugar desde el primer segmento tonal del enunciado hasta el último segmento del contorno. Además no presenta anacrusis ni primer pico. Veámoslo en el gráfico 7. Se trata de un patrón nuevo que se reveló en unas pruebas perceptivas (Font-Rotchés y Mateo, 2011) y que parece ser muy productivo.

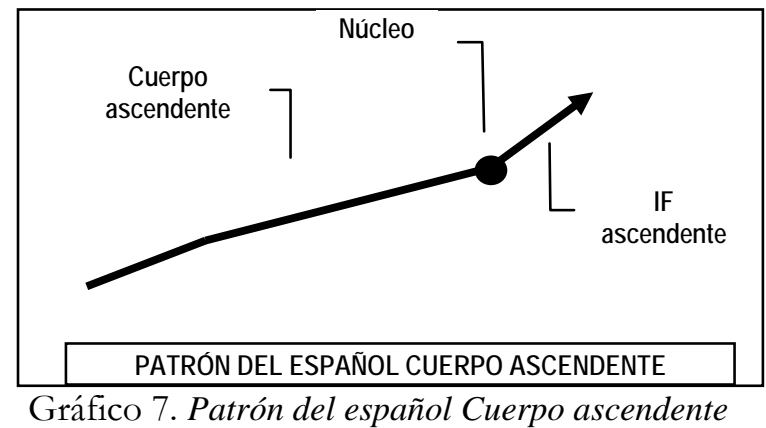

Tenemos un total de 17 enunciados con distintos ascensos que han sido reconocidos como /+interrogativos/. El ascenso total de las melodías puede ser de entre un $20 \%$ a un $140 \%$, y el ascenso de las inflexiones finales, de un 10\% hasta un $66 \%$. Cuanto más ascenso global y más ascenso en la inflexión final tienen las melodías de estos contornos, los informantes de las pruebas de percepción más los reconocen como /+interrogativos/, incluso, en algunos casos, se llega al 100\%. Presentamos a continuación algunos de los enunciados-pregunta que siguen este patrón.
a. ¿Me puedo levantar y cantar ya?
b. Pero, ¿sabes bailar?
c. ¿Y usted me fía?
d. ¿Te parece bien?
e. ¿Compraste algo?

En el gráfico 8, se representa el contorno melódico de la pregunta Pero ¿sabes bailar? que sigue las características melódicas del patrón. La línea 
melódica se inicia en el primer segmento tonal y va ascendiendo de forma constante hasta la última sílaba tónica, -lar, donde tiene lugar un ascenso final de un $12,9 \%$. El ascenso total del contorno es de un 104\%.

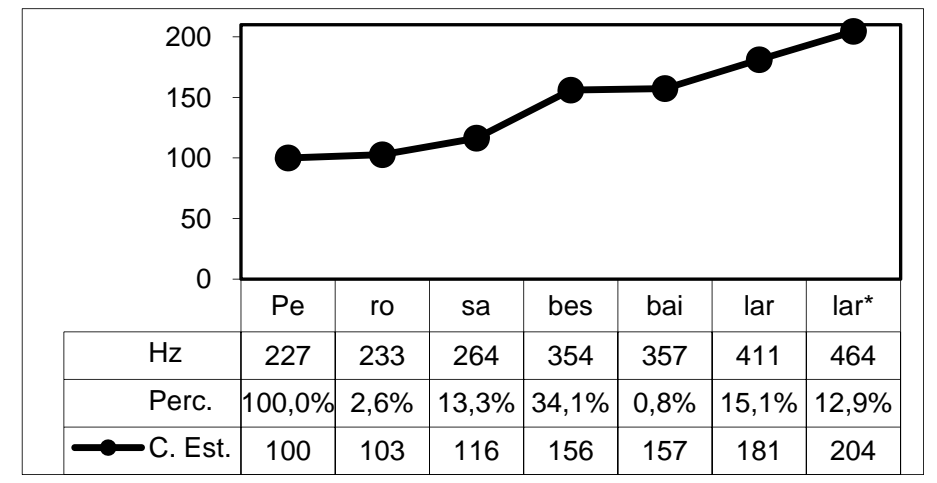

Gráfico 8. Contorno melódico de Pero ¿sabes bailar? del patrón Cuerpo ascendente del español.

\section{Patrones interrogativos del catalán}

En catalán hemos encontrado tres patrones /+interrogativos/, los cuales se han descrito a partir del análisis de un corpus y de los resultados de unas pruebas de percepción (Font-Rotchés, 2007, 2008).

Las preguntas fueron extraídas de un corpus que contiene 580 enunciados (Font-Rotchés, 2006) procedentes de 47 horas de grabaciones de TV entre 1996 y 2000 en programas en los que había diálogo (debates, reportajes, tertulias, concursos, magazines). Tenemos un total de 37 interrogativas absolutas producidas por 30 informantes, hombres y mujeres, que tienen entre 20 y 70 años con profesiones diversas.

\subsection{Elpatrón IF ascendente (+80\%)}

El patrón 3 es el patrón interrogativo por excelencia /+interrogativo -enfático -suspenso/ y se distingue de los otros porque presenta una inflexión final con un ascenso igual o superior al $80 \%$, tal como se puede apreciar en el gráfico 9 . 


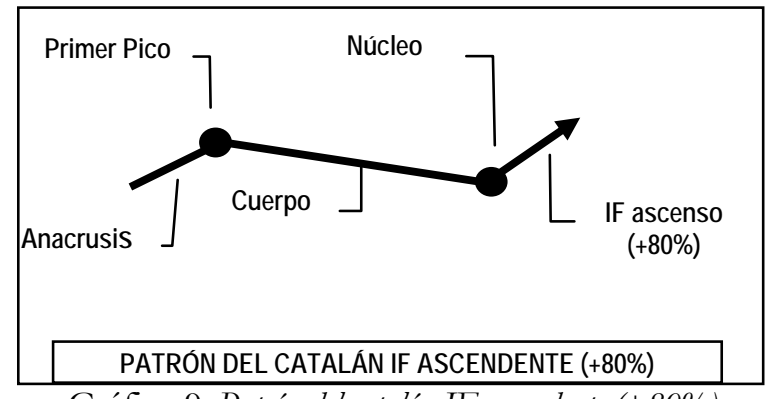

Este patrón se caracteriza por presentar un ascenso hasta la primera silaba tónica o primer pico de un máximo de un $40 \%$, un cuerpo en declinación hasta el núcleo o última sílaba tónica y un ascenso final igual o superior al $80 \%$. Tenemos un total de 26 interrogativas absolutas que responden a los rasgos melódicos de este patrón, de las cuales aportamos unos ejemplos:

a. I la pronúncia, ha anat bé? '¿Y la pronunciación fue bien?'

b. Vols dir? '¿Estás seguro?'

c. Portes bambes? '¿Llevas bambas?'

d. Fa molts anys? '¿Hace muchos años?

e. Estàs a dieta, tu? '¿Estás a dieta, tú?'

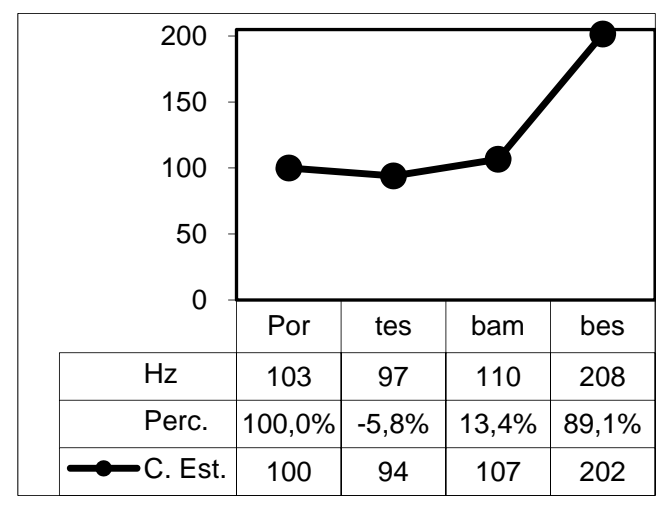

Gráfico 10 Contorno melódico de Portes bambes? ‘¿Llevas bambas?’ del patrón IF ascendente $(+80 \%)$ del catalán. 
En el gráfico 10 podemos ver el contorno de uno de los enunciadospregunta, que cumple con las características del patrón. El contorno empieza en la primera sílaba tónica o primer pico, Por-, continua en el cuerpo hasta la última sílaba tónica, bam-, y acaba con un ascenso de un $89,1 \%$ en -bes.

\subsection{El patrón Inflexión final con núcleo elevado (+50\%)}

El patrón IF con núcleo elevado $(+50 \%)$ es /+interrogativo +enfático -suspenso/ porque los informantes interpretaron que las melodías se caracterizaban con estos rasgos. Como se puede ver en el gráfico 11, se distingue de otro patrón por su inflexión final: el núcleo se encuentra en la cúspide de un ascenso igual o superior a un 50\%. Presenta una anacrusis (opcional) ascendente hasta un máximo de un 30\% hasta el primer pico, un cuerpo en declinación levemente descendente hasta la sílaba anterior a la última tónica, donde empieza un ascenso igual o superior a un 50\%, que culmina en el núcleo. Le sigue un descenso hasta situarse por debajo de la sílaba pretónica.

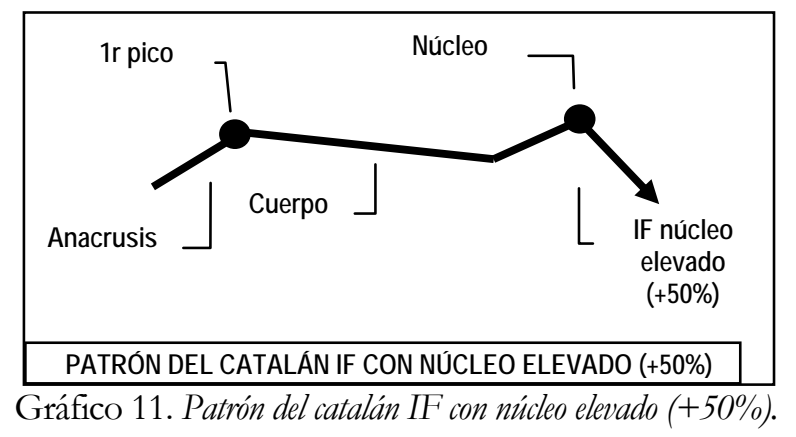

Este tipo de patrón no aparece con tanta frecuencia como el anterior (tenemos 8 enunciados-pregunta) porque requiere de un contexto en qué se emita una pregunta enfática. Estas preguntas suelen expresar duda, incredulidad, o, simplemente, son confirmatorias. Veamos unos ejemplos:
a. El pintor? '¿Elpintor?'
b. D'Andalusia? '¿De Andalucia?'
c. Que és lícit? ‘¿Es lícito?'
d. Vostè creu que és car això? '¿¿ Usted cree que es caro eso?' 
El siguiente contorno (gráfico 12) es típico del patrón con una variación poco significativa en el primer pico ya que está desplazado hacia una sílaba tónica posterior, creu. La línea melódica sigue con un descenso en el cuerpo hasta la sílaba, car. En este caso, por el hecho de ser la última palabra del contorno aguda, el punto más alto recae en la sílaba átona anterior. Así, pues, desde este punto, car, se inicia un ascenso del $56 \%$ hasta ai- y le sigue un descenso de un $58 \%$ hasta $-x \grave{o}$.

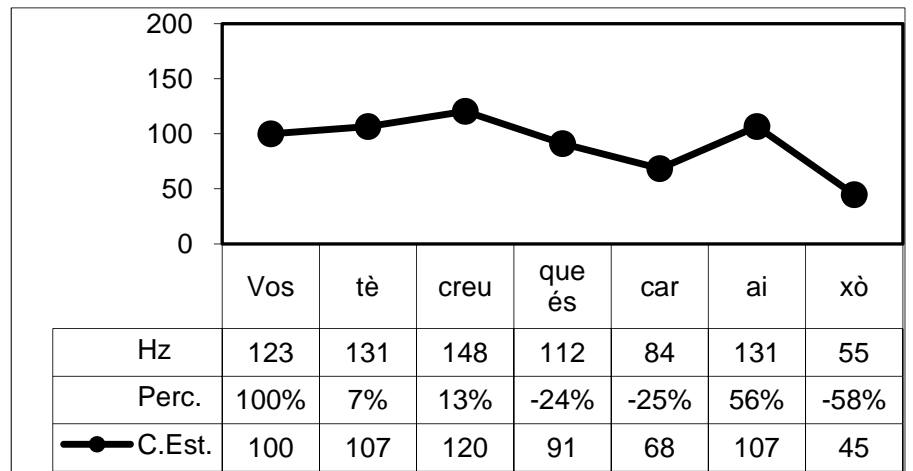

Gráfico 12. Contorno melódico de Vostè creu que és car això? 'Usted cree que es caro esto?' del patrón IF con núcleo elevado (+50\%) del catalán.

\subsection{El patrón Inflexión final descendente-ascendente (+120\%)}

El patrón IF descendente-ascendente $(+120 \%)$ es un patrón $/+$ interrogativo +enfático -suspenso/con una inflexión final circunfleja con tres valores y dos direcciones, una descendente, que puede ser más o menos pronunciada, y otra ascendente, que tiene que ser igual o superior a un $120 \%$ para que el contorno sea interpretado como pregunta (véase en el gráfico 13). Si el ascenso es inferior, el contorno se percibe como enfático. Además de esta característica en la inflexión final, el patrón se caracteriza por presentar un primer pico desplazado hacia una sílaba posterior a la primera tónica con un ascenso de hasta un $50 \%$ y un cuerpo en declinación suave y constante hasta la última sílaba tónica. Una variante de este contorno es la que presenta un ascenso en la sílaba pretónica, antes de iniciar el descenso de la primera parte de la inflexión final. 


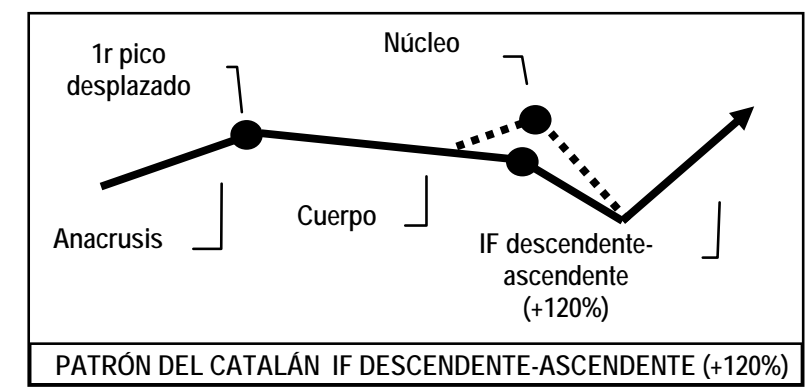

Gráfico 13. Patrón del catalán IF descendente-ascendente $(+120 \%)$.

Los contornos que responden a este patrón se utilizan poco (tenemos 3 enunciados -pregunta) ya que requieren de contextos más específicos y por ello necesitamos de un corpus muy amplio para encontrar muestras. Presentamos a continuación dos ejemplos que tienen en común que son preguntas confirmatorias.

\section{a. Un petó? '¿Un beso?' \\ b. I no li sap greu treure-se'l? ‘¿Y no le sabe mal dejarlo?}

El contorno del gráfico 14 se caracteriza por una anacrusis con un ascenso de un $27 \%$ hasta la sílaba, sap, que es posterior a la primera tónica y continúa con un descenso seguido de un ascenso muy marcado, de un $100 \%$ en $-u$; a partir de aquí, un descenso hasta el núcleo treu- donde empieza la inflexión final constituida por un descenso, de un $26 \%$, en -re, y de un ascenso de un $157,8 \%$ en $-s e^{\prime}$, último valor del contorno.

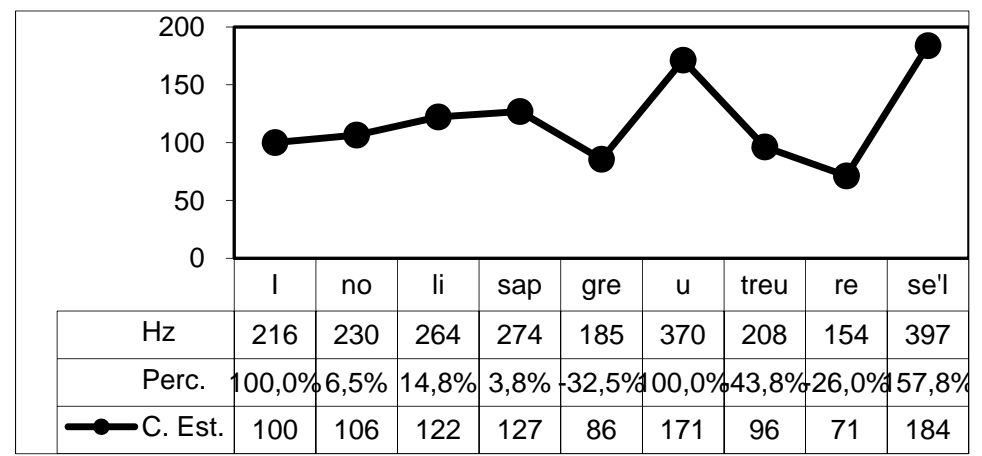

Gráfico14. Contorno melódico de I no li sap greu treure-se'l? ‘ $¿ Y$ no le sabe mal dejarlo?’ del patrón IF descendente-ascendente $(+120 \%)$ del catalán. 


\section{Patrones interrogativos del portugués de Brasil}

En portugués de Brasil hemos encontrado tres patrones /+interrogativos/ que se obtuvieron del análisis acústico y del resultado de las pruebas perceptivas de unos enunciados de un corpus de portugués de Brasil (Cantero y Font-Rotchés, en prensa).

Basamos la investigación en 40 preguntas extraídas de un corpus de 8 horas de duración. Se trataba de entrevistas y conversaciones en las que participaban 15 informantes, 12 hombres y 3 mujeres, con edades comprendidas entre 25 y 65 años, hablantes nativos del estado de Goiás (Brasil) y que trabajaban en el ámbito rural (agrónomos, ingenieros rurales, agricultores y sus esposas e hijas).

\subsection{Elpatrón Inflexión final ascendente (30\% 52\%)}

El patrón melódico IF ascendente (30 52\%) representado en el gráfico 15 que se caracteriza por ser /+interrogativo -enfático -suspenso/ presenta una anacrusis opcional, que comprende las primeras sílabas átonas del enunciado hasta la primera sílaba tónica o primer pico. En esta parte del contorno puede tener lugar un ascenso de hasta un $30 \%$ o un $40 \%$. A veces, el enunciado empieza en el primer pico y no presenta esta parte y otras el ascenso puede ser de un $50 \%$ o superior, con lo cual estamos ante un énfasis en el primer pico.

El cuerpo, que va del primer pico al núcleo, tiene tendencia a presentar un descenso casi imperceptible o a ser plano, aunque es frecuente encontrar en el cuerpo palabras que presentan un ascenso tonal. Después del núcleo, empieza la inflexión final, que se caracteriza por un ascenso leve de entre un $30 \%$ y un $52 \%$.

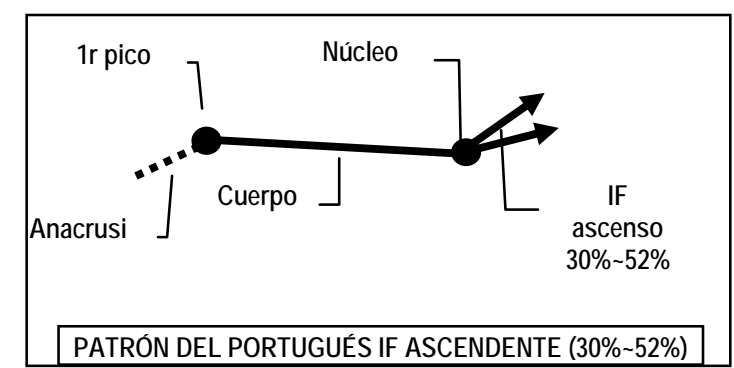

Gráfico 15. Patrón del portugués IF ascendente (30\% 52\%). 
Tenemos un total de 17 interrogativas absolutas que responden a los rasgos melódicos de este patrón, de las cuales aportamos los siguientes ejemplos:

a. Está lembrado? ‘'Te acuerdas?

b. Dos anteriores? ¿¿De los anteriores?'

c. Mas esses que você dá eles valem cinqüenta? Pero esos que tu das, ¿valen cincuenta?'

d. Você quer levar o negócio das vacas? ¿Quieres llevar el negocio de las vacas?'

e. Duzentos e cinqüenta esse bezerro? ¿¿Doscientos cincuenta ese becerro?

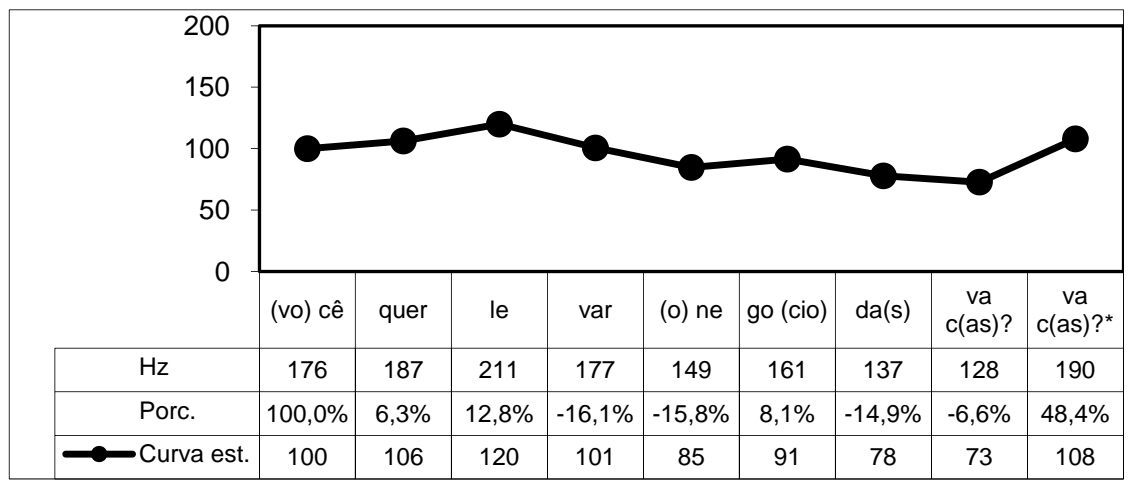

Gráfico 16. Contorno melódico de Você quer levar o negocio das vacas? ¿Quieres llevar el negocio de las vacas?' del patrón IF ascendente (30 52\%).

En el gráfico 16, la pregunta Você quer levar o negocio das vacas? ‘Usted quiere llevar el negocio de las vacas?' es un ejemplo que sigue las características de este tipo de preguntas. Presenta un anacrusis con un ascenso total de un $20 \%$ hasta el primer pico, le-, que en este caso se ha desplazado a una vocal átona posterior a la primera tónica, un cuerpo levemente descendente con un ascenso de un $8,1 \%$ en $-g o-$, y un ascenso final a partir de la última sílaba tónica, va-, de un 48,4\%.

\subsection{El patrón Inflexión final ascendente-descendente}

El patrón melódico IF ascendente-descendente (v. gráfico 17) normalmente se caracteriza por un cuerpo plano y no tiene ni anacrusis ni primer pico. En 
algunos casos, puede presentar una anacrusis opcional con un ascenso leve, que comprende las primeras sílabas átonas del enunciado hasta la primera sílaba tónica o primer pico. A partir del núcleo, empieza la inflexión final, que en este caso tiene tres valores y es circunfleja, ascendente-descendente: el ascenso que tiene lugar puede ser de un $15 \%$ a un $75 \%$ y el descenso suele llegar hasta un punto cercano de donde había empezado la inflexión final.

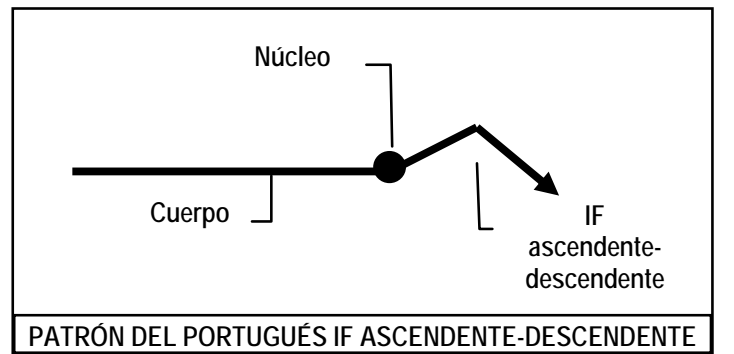

Gráfico 17. Patrón del portugués IF ascendente-descendente.

Hemos definido este patrón a partir de 11 enunciados-pregunta, algunos de los cuales ejemplificamos a continuación:

a. Você tem alguma dúvida com relação as suas, seus dados? ‘¿ Usted tiene alguna duda con relación a sus, sus datos?'

b. vinte mesmo? '¿Veinte mismo?'

c. Está vendo os morrinhos? '¿Está viendo las colinas?'

d. Você tem o anterior? '¿Tienes el anterior?'

e. Do pé de acerola? ‘¿Del árbol de acerola?

En el gráfico18 se encuentra un ejemplo típico con un cuerpo plano, sin anacrusis ni primer pico, y una inflexión final ascendente-descendente, que se inicia en -ro-, asciende un $48,4 \%$ en un alargamiento de la misma sílaba y desciende hasta $-l a$, un $29 \%$. 


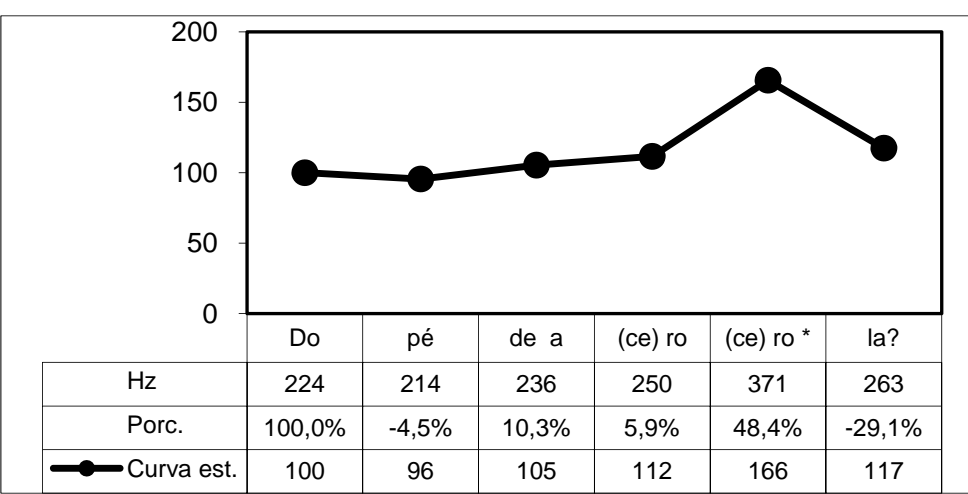

Gráfico 18. Contorno melódico de Do pé de acerola? ‘¿Del árbol de acerola?’ del patrón IF ascendente-descendente del portugués.

\subsection{Elpatrón Inflexión final con núcleo elevado (10\% 50\%)}

El patrón melódico IF con núcleo elevado $(10 \% \sim 50 \%)$ se caracteriza por una anacrusis opcional, que comprende las primeras sílabas átonas del enunciado hasta la primera sílaba tónica o primer pico (v. en el gráfico 19). En esta parte del contorno puede tener lugar un ascenso de hasta un $30 \%$ o $40 \%$. El cuerpo presenta un descenso suave hasta la sílaba anterior al núcleo, donde empieza un ascenso, que puede ser de un 10\% hasta un 50\% aproximadamente, ya que no hemos encontrado hasta el momento ejemplos con un ascenso superior. La línea melódica continúa con un descenso que acaba en el punto más bajo del contorno.

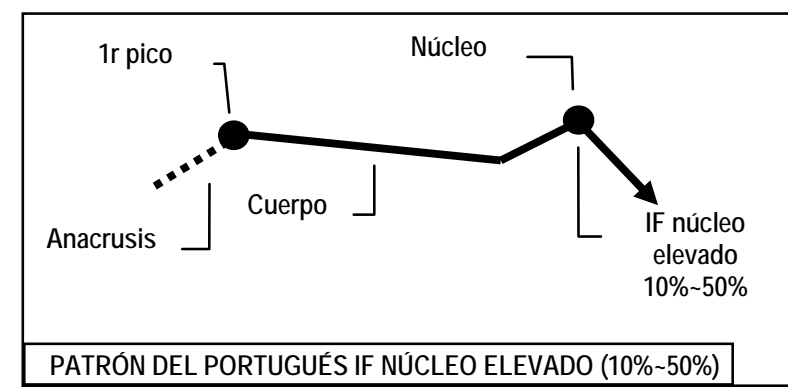

Gráfico 19. Patrón del portugués IF con núcleo elevado (10\% 50\%). 
Tenemos un total de 12 enunciados pregunta que nos han permitido definir el patrón. Presentamos a continuación unos ejemplos.

a. Desse você trouxe da última vez?? '¿Esto has traído la última vez?'

b. Você está vendo isso? ‘¿Estás viendo esto?'

c. Já pensou se aquilo lá estourar? '¿Ya pensaste si aquello explota?'

d. Tem visão aqui? '¿Se puede ver desde aquí?'

e. Mas ele não trabalba nada com o gado? 'Pero él ¿no trabaja con el ganado?'

En el gráfico 20, la melodía empieza en el primer pico o primera sílaba tónica, Tem, continúa en descenso hasta la sílaba pretónica, visao; a partir de este punto empieza el ascenso de un 16,5\% hasta la última sílaba tónica, quí, y acaba en un descenso del $20 \%$. Se trata de un caso típico.

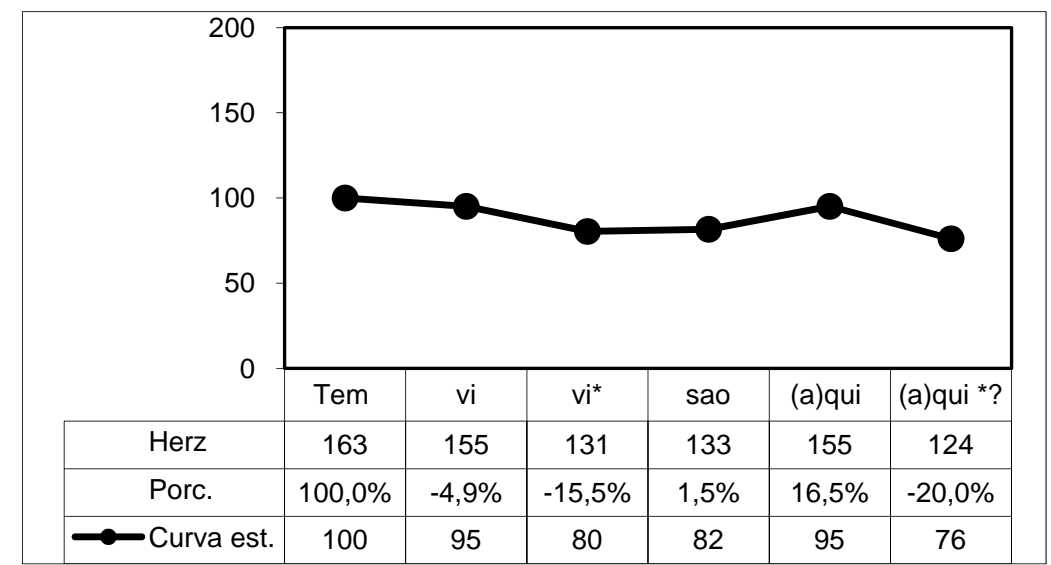

Gráfico 20. Contorno melódico de Tem visão aqui? ‘'Se puede ver desde aquí?’ del patrón IF con núcleo elevado (10\% 50\%) del portugués.

\section{Análisis comparativo de la entonación de las interrogativas absolutas del español, del catalán, y del portugués}

Después de haber presentado la descripción de los patrones melódicos de las interrogativas absolutas en tres lenguas románicas, español, catalán y portugués, vamos a comentar a continuación las semejanzas y diferencias formales que mantienen entre ellos. 


\subsection{Elpatrón IF ascendente}

Las tres lenguas presentan un patrón con una inflexión final ascendente, pero con distintos porcentajes de ascenso, tal como se puede constatar en el gráfico 21. Estos datos vienen determinados por los resultados obtenidos en las pruebas de percepción. Así, en catalán, los nativos para reconocer un enunciado como pregunta sitúan la inflexión final en un ascenso de un $80 \%$ como mínimo (en el gráfico línea negra). En español, hay dos patrones con final ascendente, uno con una inflexión final superior a un $70 \%$ (en el gráfico línea gris oscuro) y otro que se sitúa entre un $40 \%$ y un $60 \%$, pero que debe tener un primer pico desplazado. Finalmente, en portugués, el patrón ascendente lo hemos descrito con un ascenso de un 30\% a un $52 \%$ (en el gráfico líneas gris claro). Como ya hemos comentado, esta parte del contorno es la más significativa y es la que permite a los hablantes reconocer el tipo de melodía que perciben.

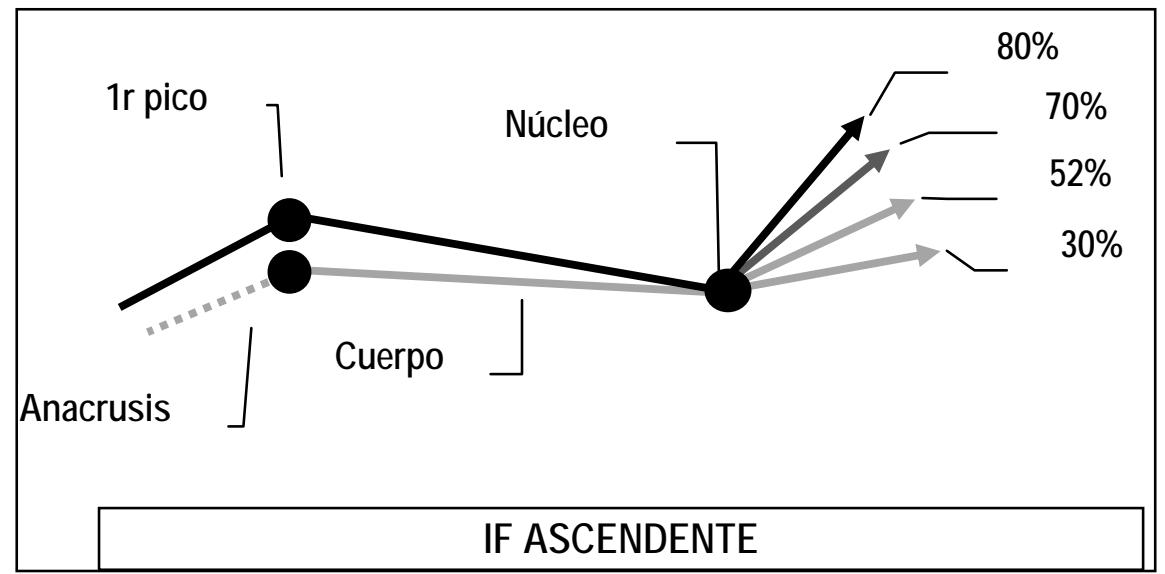

Gráfico 21. Esquema del patrón IF ascendente de las tres lenguas.

Referente al cuerpo de estos contornos, en portugués de Brasil presenta una tendencia a ser casi plano (línea gris), mientras que en catalán o en español el cuerpo es descendente (línea negra). El primer pico se encuentra en la primera sílaba tónica en todos, excepto en el patrón ascendente del español con terminación ascendente $40-60 \%$, que está en una átona posterior. 
Estas diferencias formales en la inflexión final, tan importantes para captar el significado de lo que se dice, tienen unas consecuencias directas en la enseñanza y aprendizaje de una segunda lengua o de una lengua extranjera. A los brasileños (preguntas con ascenso entre un 30\%-52\%) les va a costar mucho producir preguntas en español (a partir de un 70\%) y, aún más, en catalán $(+80 \%)$ que sean interpretadas como tales (un 100\% de ascenso equivale a una octava de la escala musical). En realidad, el patrón interrogativo del portugués de Brasil está dentro de los márgenes del patrón suspenso del español (ascenso del 15\% al 70\%) y del catalán (ascenso del $10 \%$ al 80\%). Se trata de un caso de 'falso amigo'. Por consiguiente, si el ascenso que los brasileños hacen para producir una pregunta no es suficiente, se puede entender que se trata de un enunciado no acabado y, en el caso de ascensos leves inferiores a un 10\% 15\%, se puede interpretar como un enunciado declarativo. Estos ascensos insuficientes de la inflexión final de las preguntas producidas por los brasileños al hablar en español, los cuales pueden causar dificultades en el comunicación, los han constatado en sus investigaciones Fonseca et alii (2011).

Contrariamente, un español o un catalán hablando en portugués van a producir unas preguntas con unos ascensos tan marcados que pueden ser interpretados como enfáticos y, probablemente, /- interrogativos/.

\subsection{Elpatrón IF ascendente-descendente}

El patrón IF ascendente-descendente /+interrogativo/ solo lo hemos encontrado en español y en portugués. Son muy parecidos, no solo por la inflexión final sino también porque ambos presentan un cuerpo plano. Sin embargo, en español existe una variante de este patrón que puede presentar una anacrusis y primer pico y un cuerpo descendente.

$\mathrm{El}$ ascenso que tiene lugar en la inflexión final puede ser, con los datos que tenemos hasta hoy, desde un $25 \%$ hasta un $55 \%$ en español (en el gráfico 22 líneas negras), y desde un $15 \%$ a un $75 \%$ en portugués (en el gráfico 22 líneas grises). Estas cifras máximas de ascenso proceden de los contornos que tenemos, lo cual significa que podrían existir porcentajes de ascenso más elevados. El descenso supera el punto donde empezó la inflexión final.

En el caso del catalán, este patrón existe y es enfático, aporta un significado de cortesía. Se trata nuevamente de un caso de 'falso amigo' Por lo tanto, para un nativo catalán no conocedor de estas lenguas le sería difícil 
interpretar este tipo de pregunta en español y en portugués, ya que entendería un enunciado/tenfático/ con dosis de cortesía y, evidentemente, también le sería difícil producirlo para un contexto de pregunta.

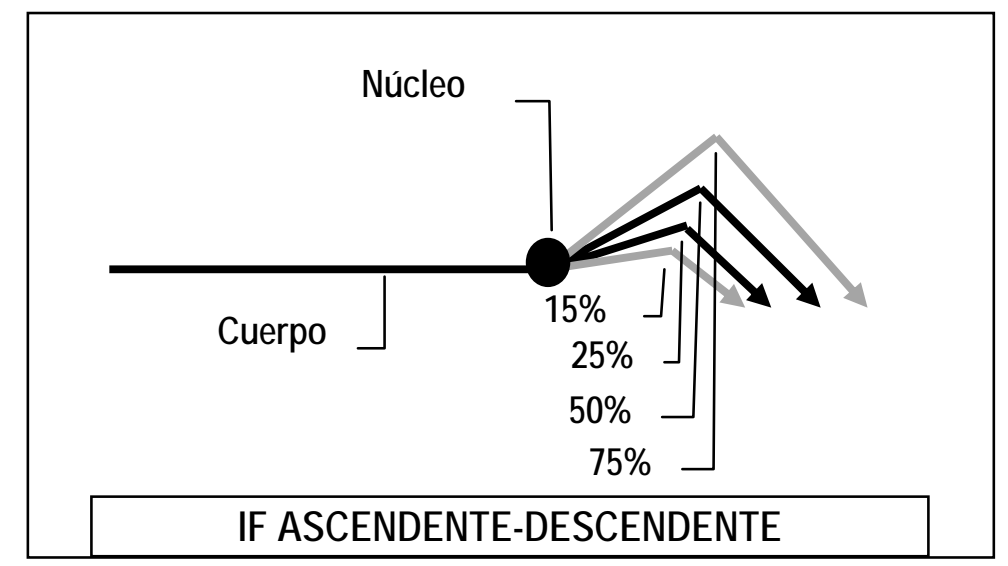

Gráfico 22. Esquema del patrón IF ascendente-descendente en español y en portugués.

\subsection{El patrón IF con núcleo elevado}

El patrón con núcleo elevado / +interrogativo/ no debe confundirse con el que hemos tratado anteriormente, IF ascendente-descendente, aunque aparentemente puede parecer que sean iguales. La diferencia está en el punto donde se encuentra la última sílaba acentuada. En el anterior, la inflexión final se caracteriza por ser circunfleja y presentar desde la sílaba acentuada hasta el final dos direcciones, ascenso y descenso, y tres valores, en cambio en este caso son dos valores y una sola dirección, un descenso (v. gráfico 23).

De este patrón se encuentran variantes en catalán y en portugués. Existen, pero, diferencias en el punto alto donde se sitúa el núcleo: en catalán, para que el enunciado sea interpretado como pregunta el núcleo debe situarse en un ascenso del 50\% como mínimo. Si el núcleo se encuentra en un punto inferior, entre un $10 \%$ y un $50 \%$, se trata de un enunciado enfático. Este último patrón /+enfático/ del catalán es el que coincide con el patrón /+interrogativo/ del portugués. Estamos ante un caso de ‘falso amigo' que puede afectar la intercomprensión entre hablantes 
de las dos lenguas. Así pues, un portugués que quiera hacer una pregunta en catalán deberá llegar a este $50 \%$ como mínimo para no provocar malentendidos y, al contrario, un catalán deberá no situar el núcleo en un punto tan alto.

Finalmente, un español no sabemos hasta qué punto reconocería este tipo de preguntas, ya que existe un patrón parecido, pero es enfático. En todo caso, debería aprender a producir preguntas del portugués o del catalán con este patrón y con el ascenso adecuado para cada lengua y adquirir, así, una buena competencia.

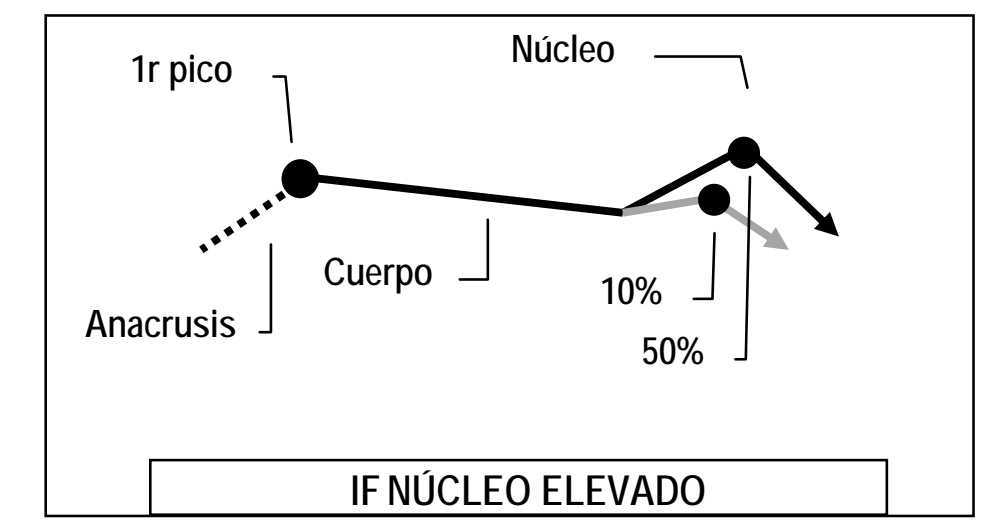

Gráfico 23. Esquema del patrón IF con núcleo elevado en catalán y portugués.

\subsection{Otros patrones}

Existen dos patrones, el patrón IF descendente-ascendente (120\%) del catalán y el patrón de Cuerpo ascendente del español, los cuales parece que no tienen correlatos en las otras dos lenguas comparadas. En el caso del patrón español, cuerpo ascendente, es un tipo de melodía muy utilizada en preguntas absolutas, por lo que se debe tener en cuenta en los procesos de enseñanza-aprendizaje de esta lengua y se debe aprender en los primeros momentos para ir desarrollando la competencia comunicativa. En cambio, el patrón IF descendente-ascendente $(120 \%)$ del catalán no es muy frecuente, ya que necesita de contextos en que se produzca una pregunta con un énfasis muy marcado. 


\section{Conclusiones}

El método Melodic Analysis of Speech (MAS) se ha utilizado para el análisis de la entonación de distintas lenguas y de la interlengua, investigaciones que han demostrado su valía y adecuación para este tipo de trabajos. El hecho que se base en el habla real de hablantes nativos y de corpus amplios junto con un análisis acústico y perceptivo exhaustivo que nos ofrece datos exactos en porcentajes de movimiento tonal es lo que favorece su aplicación no solo en la descripción lingüística sino también en el desarrollo de aplicaciones didácticas en el ámbito de la enseñanza de lenguas.

Hemos aportado la descripción de los patrones melódicos de las interrogativas absolutas de tres lenguas románicas, español, catalán y portugués, procedentes de resultados de estudios llevados a cabo en el sí del grupo Entonación y Habla. Y hemos caracterizado cada patrón con unos márgenes de dispersión amplios en cada una de sus partes: anacrusis, primer pico, cuerpo, núcleo e inflexión final, con datos exactos expresados en porcentajes.

Los datos exactos obtenidos nos han permitido llevar a cabo una comparación formal exhaustiva y constatar qué patrones /+interrogativos/ son idénticos o muy parecidos (IF ascendente-descendente del español y del portugués), cuales son semejantes (el patrón IF ascendente $(+70 \%)$ del español con el patrón IF ascendente $(+80 \%)$ del catalán), cuales constituyen falsos amigos (el patrón con núcleo elevado $(10 \% \sim 50 \%)$ del portugués coincide con un patrón enfático del catalán; en cambio, el patrón interrogativo del catalán exige un ascenso del núcleo del $50 \%$, que no tiene correlato en portugués), y cuales solo existen en una de las tres lenguas (patrón Cuerpo ascendente del español, patrón IF descendente-ascendente $(+120 \%)$ del catalán). Finalmente, hemos constatado que aunque la dirección de la inflexión final puede ser en algunos patrones compartida por las tres lenguas, no es una característica melódica suficiente para compararlos, ya que hemos visto como el rasgo melódico más significativo es el porcentaje de movimiento tonal: una melodía es interpretada de manera distinta según el porcentaje de ascenso. En este sentido, si solo tuviéramos en cuenta la dirección de la inflexión final, podríamos pensar que hay un patrón ascendente coincidente en las tres lenguas, pero, si tenemos en consideración el porcentaje de ascenso tonal de la inflexión final, constatamos que no hay ningún patrón coincidente.

Estos resultados creemos que son esenciales para los profesores que enseñan una de estas lenguas románicas para un hablante que es nativo de 
otra. Así, por ejemplo, es útil para enseñar español o catalán a un portugués o enseñar portugués a un nativo de español o de catalán.

Somos conscientes que esta es una primera parte del estudio, de tipo formal, y que el trabajo tiene que continuar con la descripción del uso pragmático de estos enunciados, para así tener una visión completa de los distintos patrones interrogativos de cada lengua y de su significado pragmático.

\section{Referencias bibliográficas}

BOERSMA，P. \& WEENINK (1992-2010), PRAAT. Doing phonetics by computer. Institute of Phonetic Sciences, University of Amsterdam. http://www.praat.org

CANTERO, F. J. (2002): Teoría y análisis de la entonación. Barcelona, Edicions de la Universitat de Barcelona.

CANTERO, F.J. y FONT-ROTCHÉS, D. (2007): "Entonación del español en habla espontánea: patrones melódicos y márgenes de dispersión", Moenia, núm. 13, 69-92.

CANTERO, F.J. y FONT-ROTCHÉS, D. (2009): "Protocolo para el análisis melódico del habla", Estudios de Fonética Experimental, núm. XVIII, 17-32.

DEVÍS, E. (en prensa): "La entonación del español hablado por italianos", Actes del XXVI Congrés Internacional de Lingüística i Filologia Romàniques. València. Universitat de València.

FONSECA, A. y CANTERO, F.J. (2011): "Características da da entonação do espanhol falado por brasileiros", Actas do VII congresso internacional da ABR ALIN, Curitiba (Brasil) 84-98.

FONT-ROTCHÉS, D. (2007): L'entonació del català. Barcelona, Publicacions de l'Abadia de Montserrat.

FONT-ROTCHÉS, D. (2008): "Els patrons entonatius de les interrogatives absolutes del català central", Llengua i Literatura, núm 19, 299-329.

FONT-ROTCHÉS, D. y CANTERO, F.J. (2009): "Melodic Analysis of Speech Method applied to Spanish and Catalan", Phonica, 5, 33-47. http:/www.ub.es/lfa (consultado 15-3-2011).

FONT-ROTCHÉS, D. y MATEO, M. (2011): "Absolute interrogatives in Spanish, a new melodic pattern", Actas do VII Congresso Internacional da ABRALIN, Curitiba (Brasil), 1111-1125. 
LIU, Y.H. (2005): La entonación del español hablado por taiwaneses, Biblioteca Phonica, 2. http:/www.ub.es/lfa (consultado 15-3-2011).

MARTORELL, L. (en prensa): "Les interrogatives absolutes de l'espanyol parlat per suecs", Phonica, 7.

PÁLVÖLGYI, K. (2010): "Fenòmens tonals conflictius en la llengua catalana i l'hongaresa investigats en la interllengua hongaresacatalana”, Actes del Catorzè Col-loqui Internacional de Llengua i Literatura Catalanes, Publicacions de l'Abadia de Montserrat, vol. III, 233-247. 